\title{
Photoinduction of UV-absorbing compounds in Antarctic diatoms and Phaeocystis antarctica
}

\author{
Lieselotte Riegger, Dale Robinson*
}

Alfred Wegener Institute for Polar and Marine Research, Am Handelshafen 12, D-27570, Bremerhaven, Germany

\begin{abstract}
The presence of UV-absorbing compounds, their in vivo absorption and photoinducibility were investigated in the colonial form of the prymnesiophyte Phaeocystis antarctica and 11 species of Antarctic diatoms. High in vivo phytoplankton absorption peaks centered at $315-320 \mathrm{~nm}$ wavelengths indicated the presence of UV-absorbing compounds in all cultures of $P$. antarctica examined. UVabsorbing compounds, detected as in vivo absorption peaks at slightly longer wavelengths (330-333 nm), were present in most diatom species, but were absent or present in minute amounts in smaller species. UV-absorbing compounds were identified in the diatoms as the mycosporine-like amino acids (MAAs) porphyra-334, mycosporine-glycine, and shinorine but could not be positively identified in $P$. antarctica. Accumulation of MAAs was induced by light in the blue/UV portion of the spectrum (305-460 nm). For diatoms, induction was most effective at wavelengths between 370 and $460 \mathrm{~nm}$ with very little response observed at ultraviolet-B (UVB, 280-320 nm) wavelengths. In contrast, induction was maximal at $340 \mathrm{~nm}$ and significant at wavelengths down to $305 \mathrm{~nm}$ in colonies of $P$. antarctica. Induction required continuous illumination and exhibited an initial lag phase (10 to $24 \mathrm{~h}$ in length), an exponential phase (60 to $120 \mathrm{~h}$ in length), and a steady-state phase. The cellular content of MAAs was stable in viable cells kept for over 2 mo in prolonged darkness and became diluted through successive cell divisions in cells grown in non-inducing lllumination (red and yellow light). The potential sunscreening effect $(S)$ of MAAs, calculated as the fractional reduction of UV exposure to a centrally-located cellular target, ranged from 0.03 to 0.50 for diatom cells and from 0.65 and 0.72 for $P$, antarctica colonies. $S$ exhibited an increasing trend with cell and colony size. Whereas MAAs are thought to be intracellularly located, the large values of $S$ determined for $P$. antarctica suggests that UV-absorbing compounds associated with the colonies are located within the extracellular colonial matrix. The results indicate that most phytoplankton species examined have the potential to respond to an increase in UVR resulting from seasonal changes in solar zenith angle by increasing their MAA content. A similar response to elevated UVB levels resulting from depleted ozone concentrations may be limited to $P$. antarctica
\end{abstract}

KEY WORDS: Mycosporine-like amino acids MAAs UV radiation Antarctica Phytoplankton Photoinduction Phaeocystis Diatoms

\section{INTRODUCTION}

The extent of biological harm resulting from naturally occurring levels of ultraviolet radiation (UVR, $280-400 \mathrm{~nm}$ ) may depend on solar radiation both as a source of damage and as a source of regulatory information. Organisms have developed a broad range of

\footnotetext{
- Present address and address for correspondence: Universities Space Research Association, National Aeronautics and Space Administration, Goddard Space Flight Center, Code 971, Greenbelt, Maryland 20771, USA

E-mail:dale@neptune.gsfc.nasa.gov
}

adaptive strategies that may reduce the impact of solar UVR (for overview see Vincent \& Roy 1993, Karentz 1994), which include repair of UVR-induced damage to DNA (Sancar \& Sancar 1988, Karentz et al. 1991b) and the production of UV-absorbing substances that act as UV sunscreens (Caldwell et al. 1983, Karentz et al. 1991a). There is a growing body of evidence that UVR and blue light play an important role in the regulation of mechanisms for acclimation to UVR. For example, gene regulation of the key enzyme of the flavonoid biosynthetic pathway, chalcone synthase, has been shown to be directly regulated by ultraviolet-A (UVA, $320-400 \mathrm{~nm}$ ) and blue light (Strid et al. 1994). Flavo- 
noids are the substances that provide sunscreen protection in higher plants (Beggs \& Wellmann 1994, Stapleton \& Walbot 1994). Recent work indicates that UV-absorbing compounds present in Antarctic phytoplankton function as UVR sunscreens (Helbling et al. 1996) and that the abundance of these compounds is regulated by the exposure of phytoplankton cells to UVR and blue radiation (Carreto et al. 1990b).

The most commonly identified class of UV-absorbing compounds in phytoplankton are mycosporine-like amino acids (MAAs), which are water-soluble substances composed of a cyclohexenone ring with an amino acid side group (Karentz et al. 1991b). Over a dozen different MAAs have been reported (Nakamura et al. 1982, Dunlap et al. 1986, Carreto et al. 1990a, Karentz et al. 1991b, Shick et al. 1992, Davidson et al. 1994), each exhibiting distinct absorption maxima in the range from 310 to $360 \mathrm{~nm}$. The cellular regulation of MAAs has not been well documented, but the results of several studies indicate that MAA accumulation in phytoplankton may respond to the quantity and spectral distribution of visible and UV light. For natural phytoplankton samples collected in the Southern Ocean, the highest concentrations of UV-absorbing compounds were found in surface samples (Mitchell et al. 1989, Vernet et al. 1989, 1994, Helbling et al. 1994), where light levels are highest. A similar depth dependency for UV-absorbing compounds was observed in corals (Dunlap et al. 1986). Furthermore, irradiation with sub-lethal doses of UVR in the laboratory and in situ enhanced the accumulation of UV-absorbing compounds in algae (Carreto et al. 1990b, Marchant et al. 1991) and cyanobacteria (Garcia-Pichel \& Castenholz 1993).

If the induction of UV-absorbing compounds in marine organisms is regulated by visible and UV light, then the characterization of that regulation could provide insight into the potential for phytoplankton to respond to variation in UV radiation brought on by seasonal changes in solar elevation and by changes in atmospheric ozone concentration. In this study, we examined the kinetics and spectral response of photoinducibility of UV-absorbing compounds, their loss in non-inducing illumination conditions, and their absorption characteristics in 11 Antarctic diatom species and in colonies of the prymnesiophyte Phaeocystis antarctica. The results are discussed in terms of the potential for UV-absorbing compounds to provide protection from UV damage.

\section{MATERIALS AND METHODS}

Phytoplankton species. The 11 diatom species, Porosira pseudodenticulata (Hustedt) Jousé, Thalas- siosira tumida (Janisch) Hasle, Thalassiosira antarctica Comber, Chaetoceros sp. 1, Chaetoceros sp. 2, Proboscia inermis (Castracane) Jordan \& Ligowski, Porosira glacialis (Grun.) Jørg., Cosinodiscus centralis Ehr, Stellarima microtrias (Ehrenberg) Hasle \& Sims, Fragilariopsis linearis (Castracane) Frenguelli, and Fragilariopsis cylindrus (Grun.) Krieger in Helmcke \& Krieger, and the prymnesiophyte Phaeocystis cf. antarctica were obtained from the collection of polar phytoplankton species at the Alfred Wegener Institute. All species were isolated from the plankton of the Weddell Sea, Antarctica. The cultures were maintained in batch culture in filter-sterilized $(0.2 \mu \mathrm{m}$ mesh size) Antarctic sea water (33 psu) enriched with Drebes Medium (Stosch \& Drebes 1964) at $0^{\circ} \mathrm{C}$. P. antarctica was maintained in the colonial phase.

Light fields and spectral measurements. Experimental incubations were carried out in refrigerated incubators that maintained temperature at $0 \pm 0.3^{\circ} \mathrm{C}$. Four different light fields were used to illuminate the algal cultures, depending on experimental requirements. A white-light field, which provided photosynthetically active radiation (PAR) at wavelengths between 400 and $700 \mathrm{~nm}$, was generated with a bank of 5 white fluorescent tubes (Osram L 40W/25). Irradiance was adjusted with acetate neutral density filters. A yellow-light (>460 nm) and a red-light (>560 nm) field were obtained by placing a yellow or red acetate filter (No. 401 and No. 482, Strand Lighting, Wolfenbüttel-Salzdahlum, Germany), respectively, before the white-light source. A full spectrum light field (UVB/UVA/PAR, 280-700 nm) was generated by 2 white fluorescent tubes, 2 UVA fluorescent tubes (Philips TL60W/09N) and 1 UVB fluorescent tube (Philips TL 40W/12).

Measurements of the white, yellow, and red light fields were made with a LICOR (LI) PAR light meter equipped with a $4 \pi$ sensor (LICOR-LI 193SB). Spectral irradiance $(280-700 \mathrm{~nm})$ was measured using a custom built non-scanning double monochromator $(1.3 \mathrm{~nm}$ resolution) with a microchannel plate detector (Tüg \& Baumann 1994).

Experimental design. To survey phytoplankton species for UV-absorbing compounds, the diatoms were incubated at the standard conditions of $100 \mu \mathrm{mol}$ photons $\mathrm{m}^{-2} \mathrm{~s}^{-1}$ of white light illumination at $0 \pm 0.3^{\circ} \mathrm{C}$. After incubation for a minimum of 5 generations, the cultures were sampled for measurements of cell number and size, algal absorption, and MAA content. To obtain 3 size classes of the prymnesiophyte Phaeocystis antarctica with colonies of uniform radius, stock cultures were first filtered over gauze mesh with 500, 100 or $20 \mu \mathrm{m}$ mesh size. Filtered colonies were resuspended in enriched Drebes Medium and allowed to grow at standard conditions for a minimum of 5 gener- 
ations, after which the radii of $80 \%$ of the colonies in each of the 3 size classes fell within the desired ranges of 50-100. 200-400 and $800-1400 \mu \mathrm{m}$. The P. antarctica cultures were sampled for measurements of colony number and size, algal absorption, and MAA content.

To examine the dependence of the accumulation of UV-absorbing compound on irradiance and spectral distribution, maintenance cultures of the diatoms Thalassiosira tumida, $T$. antarctica, and Porosira pseudodenticulata were subdivided and then incubated in red and yellow light $(100 \mu \mathrm{mol}$ photons $\mathrm{m}^{-2} \mathrm{~s}^{-1}$ ) and at 7 or 8 different intensities of white light, ranging from 20 to $350 \mu \mathrm{mol}$ photons $\mathrm{m}^{-2} \mathrm{~s}^{-1}$. After the cultures had grown in semi-continuous culture for a minimum of 10 generations, samples were taken for determination of cell number, cell size, algal absorption, and the cellular content of MAAs.

To examine the wavelength-dependent accumulation of UV-absorbing compounds at higher resolution (narrow wavelength bands), semi-continuous cultures of Phaeocystis antarctica, Porosira pseudodenticulata, and Thalassiosira tumida were maintained for a minimum of 20 generations continuously illuminated with the yellow light field $(100 \mu \mathrm{mol}$ photons $\mathrm{m}^{-2} \mathrm{~s}^{-1}$ ). This procedure prevented induction and produced algal cultures that exhibited low absorption in the UV wavelengths. Cultures in early exponential phase were dispensed in $1500 \mathrm{ml}$ aliquots into 5 open Plexiglas (GS231, Röhm GmbH, Darmstadt, Germany) enclosures that were shielded on the sides to exclude stray light. Each of 4 of the enclosures was covered with a different $3 \mathrm{~mm}$ long-pass cutoff filter (WG 320 , WG 335, WG 360 or GG 420 ; Schott. Mainz, Germany) with 50\% transmittance wavelengths at 320, 335, 360 and $420 \mathrm{~nm}$ respectively (Fig. 1). The remaining enclosure was covered with a combination of the GG 420 and the yellow acetate filter (No. 401) that passed wavelengths $>460 \mathrm{~nm}$.

To begin the experiment, illumination was provided from above by the UVB/UVA/PAR light field, resulting in a different spectral distribution in each of the enclosures (Fig. 1, Table 1). Samples for determination of cell numbers, cell size, algal absorption, and chl a concentration were taken at the beginning of the experi-
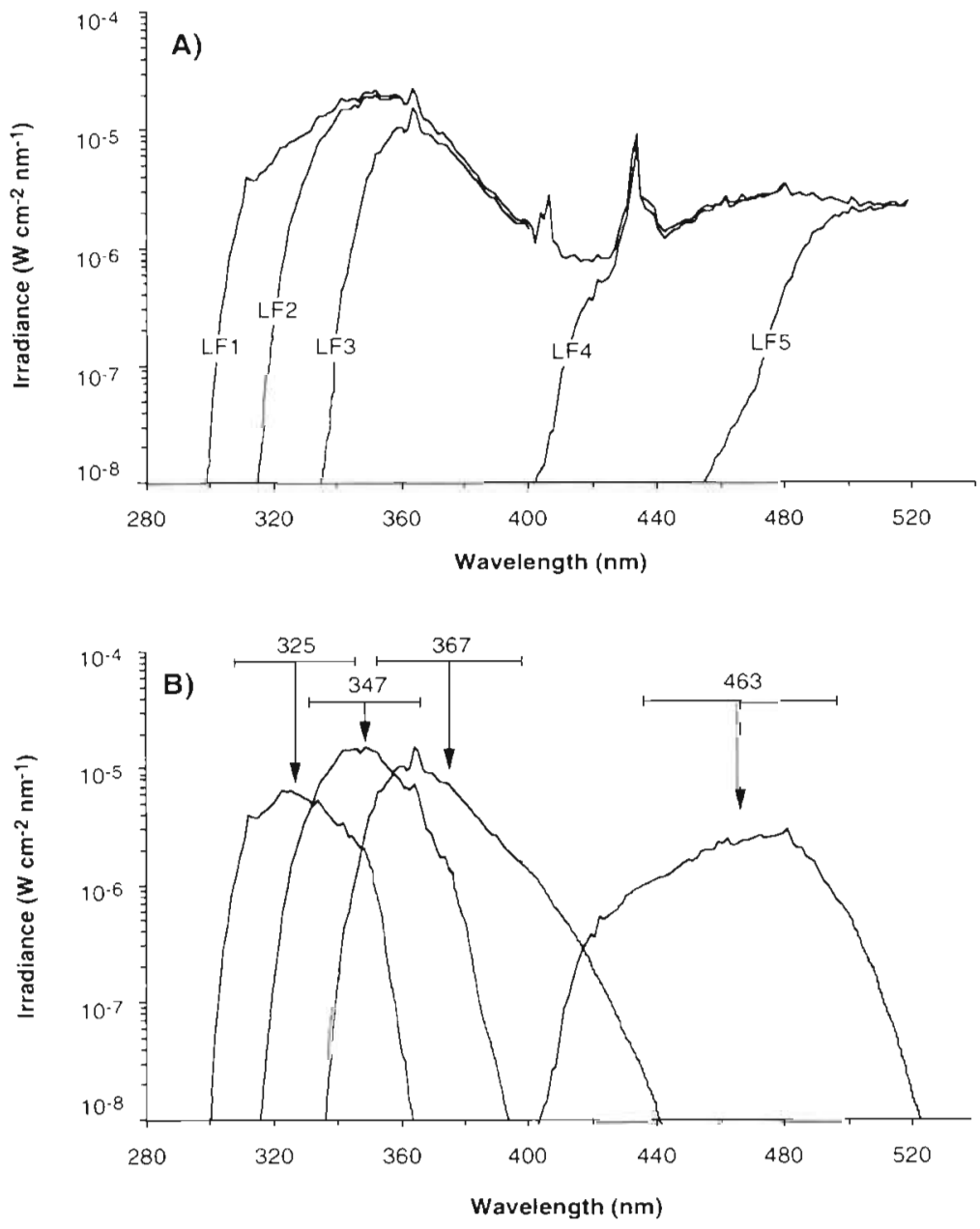

Fig. 1. (A) Spectral distribution of irradiance for 5 light fields (LF) produced when the UVA/UVB/PAR-light field was passed through 5 different longpass cutoff filters (LF1 $=W G 320, L F 2=W G 335, L F 3=W G 360, L F 4=$ GG 420, LF5 = GG $420+$ No. 401). Phytoplankton cultures were grown in these light fields to generate the response curves for the accumulation of UVabsorbing compounds. (B) Difference spectra were calculated by subtracting, wavelength per wavelength, any 2 successively numbered light field spectra presented in (A). For example, the LF1 spectrum was subtracted from the LF2 spectrum to generate difference spectrum 325 . The 4 difference spectra are defined as: $325=\mathrm{LF} 1-\mathrm{LF} 2,347=\mathrm{LF} 2-\mathrm{LF} 3,367=\mathrm{LF} 3-\mathrm{LF} 4$, and $463=$ LF $4-$ LF5. Bars at the top of the graph represent the wavelength range containing $90 \%$ the energy in each irradiance band. The spectra are labeled with the median wavelength of the irradiance bands

ment and after the onset of illumination at 12 to $24 \mathrm{~h}$ intervals. To maintain the cultures in exponential growth the cultures were diluted at each sampling step to approximately the initial cell concentration. The experiments were concluded after 4 to $6 \mathrm{~d}$ and samples were taken for identification and quantification of MAAs.

To examine the effect of prolonged periods of darkness on the accumulation of UV-absorbing compounds, semi-continuous cultures of Thalassiosira antarctica and Porosira pseudodenticulata were 
Table 1. Total irradiance (E, $280-700 \mathrm{~nm}$ ) and the fraction of the total in the UVB $(280-320 \mathrm{~nm})$ and the UVA $(320-400 \mathrm{~nm})$ for the spectral distributions used in illuminatung algal cultures. Spectral distributions are labeled numerically as in Fig. 1A

\begin{tabular}{lccc|}
\hline $\begin{array}{l}\text { Spectral } \\
\text { distribution }\end{array}$ & $\begin{array}{c}E \\
\left(\mathrm{~W} \mathrm{~m}^{-2}\right)\end{array}$ & $\begin{array}{c}\text { UVB } \\
(\% \text { of } \mathrm{E})\end{array}$ & $\begin{array}{c}\text { UVA } \\
(\% \text { of } \mathrm{E})\end{array}$ \\
\hline LF1 & 15.9 & 3.2 & 57.0 \\
LF2 & 14.0 & 0.07 & 54.3 \\
LF3 & 9.9 & 0.002 & 33.4 \\
LF4 & 6.4 & 0 & 0 \\
LF5 & 6.4 & 0 & 0 \\
\hline
\end{tabular}

maintained at continuous white-light illumination (100 $\mu \mathrm{mol}$ photons $\mathrm{m}^{-2} \mathrm{~s}^{-1}$ ) for at least 10 generations The cultures in early exponential phase were then transferred to dark conditions and maintained for $62 \mathrm{~d}$ To ensure total darkness, the flasks were covered with aluminum foil and wrapped in black cloth. At the beginning of the experiment and at intervals of 10 to $22 \mathrm{~d}$, samples were withdrawn for determination of cell number, algal absorption, and chlorophyll a concentration.

Chlorophyll a measurement. Cells from algal cultures (10 to $100 \mathrm{ml}$ aliquots) were collected under gentle filtration onto glass fiber filters (GF/C Whatman, $25 \mathrm{~mm}$ ), homogenized in $90 \%$ acetone and extracted for $2 \mathrm{~h}$ at $4^{\circ} \mathrm{C}$. Chlorophyll a determinations were made using the fluorometric method of Evans et al. (1987).

Cell counting and microscopy. Samples of algal cultures $(20 \mathrm{ml}$ ) were placed in plastic vials and fixed with formalin (buffered with Na-hexamin) at a final concentration of $1 \%$. Diatom cells were enumerated and their linear dimension determined (valve diameter and length) under an inverted microscope (Utermöhl 1958). Cell volume was calculated, assuming the diatoms were cylindrical. Phaeocystis antarctica colonies were enumerated and colony diameters were measured under an inverted microscope. Estimate of cell size were also made. Cells per colony $\left(C_{N}\right)$ were calculated using the equation of Rousseau et al. (1994)

$$
\log C_{N}=0.51 \log V+3.67
$$

where $V$ is the colonial volume expressed in $\mathrm{mm}^{3}$. Total concentration of cells was calculated from cells per colony and colony size distribution in the culture.

In vivo absorption measurements and sunscreen factors. Algal absorption was determined using a UVvisible spectrophotometer (Varian Cary 3E) fitted with an integrating sphere. Six ml of culture were cleared of particles by gentle filtration through a syringe filtration cartridge (0.2 $\mu \mathrm{m}$ mesh) and the filtrate was collected. Two matched quartz cuvettes $(1 \mathrm{~cm}$ path-length) filled with the filtrate were placed in the reference and sample position of the spectrophotometer and used to zero the spectrophotometer. The fluid in the sample cuvette was replaced with culture and the absorption spectrum determined ( $\lambda=250$ to $750 \mathrm{~nm}$ )

Sunscreen factors ( $S$ ) were calculated according to the equation of Garcia-Pichel (1994)

$$
S=\frac{J_{\mathrm{tot}}-J_{\mathrm{bkg}}}{1-J_{\mathrm{bkg}}}
$$

where $J_{t o t}$ is the efficiency factor for self-shading for the entire cell and $J_{\mathrm{bkg}}$ is the efficiency factor for selfshading for components of the cell not induced by the light treatments used in this study. $J$ was calculated from

$$
J_{\text {tot }} \text { and } J_{\mathrm{bkg}}=1-\frac{1}{a_{s} R}-\frac{\mathrm{e}^{-2 a_{s} R}-1}{2\left(a_{s} R\right)^{2}}
$$

where $R$ is the radius of the cell or colony and $a_{s}$ is the absorption coefficient at the wavelength of maximum absorption in the UV determined from in vivo algal absorption measurements. $J_{\text {tot }}$ was determined from cultures grown under illumination conditions that induced the production of UV-absorbing compounds and $J_{\mathrm{bkg}}$ was determined from cultures grown under non-inducing illumination conditions. Mean cell volume between induced and non-induced cultures was not significantly different. For non-spherical cells, $R$ was the radius of a sphere equal in volume to the mean cell volume of the culture.

Quantification and identification of UV-absorbing compounds. A relative measure of the accumulation of UV-absorbing compounds was obtained from ethanol extracts of the algal cells. Cells from algal cultures (50 to $100 \mathrm{ml}$ aliquots) were collected under gentle filtration onto glass fiber filters (GF/C Whatman). The filters were extracted in $80 \%$ ethanol for $24 \mathrm{~h}$ at $4^{\circ} \mathrm{C}$ in the darkness. Extraction efficiencies were $>96 \%$. This procedure also extracted the photosynthetic pigments. The extracts were centrifuged $(3000 \times g, 10 \mathrm{~min})$ and the supernatant was decanted and saved. Absorption spectra $(250-750 \mathrm{~nm})$ of the ethanol supernatant were recorded with a scanning spectrophotometer (PU8 720 UV/Vis Spectrophotometer, Philips). The cellular content of UV-absorbing compounds was determined as the measured absorption coefficient of the extract at the wavelength of maximum absorption in the UV normalized to cell number ( $a_{U V} /$ cell, units $\left.=\mathrm{cm}^{2} \mathrm{cell}^{-1}\right)$. Direct cell counts could not be obtained for Phaeocystis antarctica because of the colonial growth habit of the species. Therefore, the relative quantity of UVabsorbing compounds associated with $P$. antarctica is expressed as absorption at the UV maximum normalized to the absorption at the chlorophyll a red peak at $664 \mathrm{~nm}\left(\mathrm{a}_{\mathrm{UV}} / \mathrm{a}_{664}\right)$. 
MAAs were separated by reverse-phase high-performance liquid chromatography (HPLC) (Nakamura et al. 1982, Dunlap \& Chalker 1986) using a Waters 600MS HPLC system. Cells and associated particles from algal cultures (50 to $100 \mathrm{ml}$ aliquots) were collected under gentle filtration onto glass fiber filters (GF/C Whatman). The filters were placed in cryovials and immediately frozen in liquid nitrogen. The filters were then transferred to a freezer $\left(-70^{\circ} \mathrm{C}\right)$ for storage and analyzed within 12 mo of collection. The frozen filters were extracted in the dark for $24 \mathrm{~h}$ at $4^{\circ} \mathrm{C}$ in $25 \%$ methanol and filtered through glass fiber filters (GF/C Whatman) to remove particles. The filtrate was applied to an RP-8 column $(25 \mathrm{~cm}$, Waters) that was protected by an RP-8 guard column ( $1 \mathrm{~cm}$, Waters). The MAAs were eluted with an isocratic mobile phase [15\% methanol and $0.06 \%$ acetic acid $(v / v)]$ at a flow rate of $0.7 \mathrm{ml} \mathrm{min}^{-1}$ at $20^{\circ} \mathrm{C}$ and detected by absorption measured with a Waters 966 photodiode array UV/visible detector. Individual MAAs were identified from retention times and absorption characteristics using pigment standards and were quantified using the integrated peak area and the published molar extinction coefficients (Takano et al. 1978). In the case of the unstable mycosporine-glycine the extinction coefficient for the stable methyl-ester (Ito \& Hirata 1977) was used as described in Dunlap \& Chalker (1986).

Response spectra. For each phytoplankton species, MAA induction (measured as $a_{U V} / a_{664}$ ) was determined at the steady-state stage (see 'Results') of MAA accumulation from algal cultures grown under 5 different light fields (LF1 to LF5; see Fig. 1 and Table 1). To generate a response spectrum, the difference in MAA induction in cultures grown under 2 sequentially numbered light fields was divided by the difference in total irradiance (obtained by subtraction) between these 2 light fields (LF1 - LF2, LF2 - LF3, LF3 - LF4, LF4 - LF5; see Fig. 1A, B). The median wavelengths for the spectra of the resulting 4 light field pairs, determined to be $325,347,367$, and $463 \mathrm{~nm}$, were used for the $x$-axis coordinate to generate the response spectra.

\section{RESULTS}

\section{UV-absorbing compounds}

Absorption maxima centered at 330-333 nm were observed in the in vivo absorption spectra of most of the Antarctic diatoms surveyed (Fig. 2), which indicates the presence of UV-absorbing compounds in association with the algae. The exceptions were the smaller species, Chaetoceros sp. 1 and Fragilariopsis cylindrus (see Table 2 for cell radii), for which no or very small absorption peaks in the UVA and UVB were observed. UV ab- sorption per cell ( $a_{U V} /$ cell) varied by over 4 orders of magnitude among all diatom species and clones surveyed (Table 2). Bidigare et al. (1996) and Helbling et al. (1996) also noted variability in the presence and inducibility of UV-absorbing compounds among species of Antarctic diatoms. In the prymnesiophyte, $P$, antarctica, a peak was observed in the in vivo absorption spectra at wavelengths between 315 and $320 \mathrm{~nm}$ and the UV peak relative to the red peak was much greater than that observed in the diatoms (Fig. 2).

The MAA composition in Porosira pseudodenticulata was comprised of porphyra-334, mycosporine-glycine, and shinorine, representing ca 75,20 , and $5 \%$ by weight of total MAAs, respectively. For all other diatom species examined, porphyra-334 was the predominant MAA, representing ca $95 \%$ of total MAA composition, with shinorine accounting for the remaining ca $5 \%$. Other studies also reported that porphyra334 and shinorine were the dominate MAAs in Antarc-

Table 2. Cell and colony radius, content of MAAs, and estimated values of sunscreen-factor, $S$, for (a) 11 diatom species and (b) 3 Phaeocystis antarctica cultures with different colony size ranges. Numbers in parentheses indicate separate clones for a species. The relative content of MAAs is presented as $a_{U V} /$ cell for diatoms and $a_{U V} / a_{664}$ for $P$. antarctica. $S$ values were calculated for $P$. antarctica using cells and colonies as the optical unit. The cultures were grown for a minimum of 5 generations under standard conditions of $100 \mu \mathrm{mol}$ photons $\mathrm{m}^{-2} \mathrm{~s}^{-1}$ of white-light illumination at $0^{\circ} \mathrm{C}$

\begin{tabular}{|c|c|c|c|c|}
\hline \multicolumn{2}{|l|}{ (a) Diatoms } & $\begin{array}{c}\text { Valve radius } \\
(\mu \mathrm{m})\end{array}$ & $\begin{array}{c}a_{U V} / \text { cell } \\
\left(\mathrm{cm}^{2} \text { cell }\right. \\
\left.\times 10^{-6}\right)\end{array}$ & $S$ \\
\hline \multicolumn{2}{|c|}{ Thalassiosira tumida } & 12.9 & 10.0 & 0.47 \\
\hline \multicolumn{2}{|c|}{ Thalassiosira antarctica (1) } & 11.1 & 3.9 & 0.34 \\
\hline \multicolumn{2}{|c|}{ Thalassiosira antarctica (2) } & 24.4 & 17.0 & 0.43 \\
\hline \multicolumn{2}{|c|}{ Porosira pseudodenticulata } & (1) 21.2 & 25.9 & 0.50 \\
\hline \multicolumn{2}{|c|}{ Porosira pseudodenticulata } & (2) 30.0 & 35.1 & 0.47 \\
\hline \multicolumn{2}{|c|}{ Chaetoceros sp. 1} & 4.7 & 0.1 & 0.09 \\
\hline \multicolumn{2}{|c|}{ Chaetoceros sp. 2} & 5.8 & 1.0 & 0.22 \\
\hline \multicolumn{2}{|c|}{ Proboscia inermis } & 2.1 & 0.8 & 0.04 \\
\hline \multicolumn{2}{|c|}{ Porosira glacialis } & 14.1 & 11.5 & 0.40 \\
\hline \multicolumn{2}{|c|}{ Stellarima microtrias } & 11.7 & 2.6 & 0.26 \\
\hline \multicolumn{2}{|c|}{ Cosinodiscus centralis } & 23.1 & 68.2 & 0.50 \\
\hline \multicolumn{2}{|c|}{ Fragilariopsis linearis } & 2.2 & 0.05 & 0.05 \\
\hline \multicolumn{2}{|c|}{ Fragilariopsis cylindrus } & 1.5 & 0.003 & 0.03 \\
\hline \multicolumn{5}{|c|}{ (b) P. antarctica } \\
\hline \multicolumn{2}{|c|}{ Colony size Optical unit } & $\begin{array}{c}\text { Radius } \\
(\mu \mathrm{m})\end{array}$ & $a_{U V} / a_{664}$ & $S$ \\
\hline \multirow[t]{2}{*}{ Small } & Colony & $50-100$ & 18.5 & 0.65 \\
\hline & Cell & 3.5 & & 0.76 \\
\hline \multirow[t]{2}{*}{ Middle } & Colony & $200-400$ & 25.2 & 0.70 \\
\hline & Cell & 3.5 & & 0.87 \\
\hline \multirow[t]{2}{*}{ Large } & Colony & $800-1400$ & 48.3 & 0.72 \\
\hline & Cell & 3.5 & & 0.94 \\
\hline
\end{tabular}



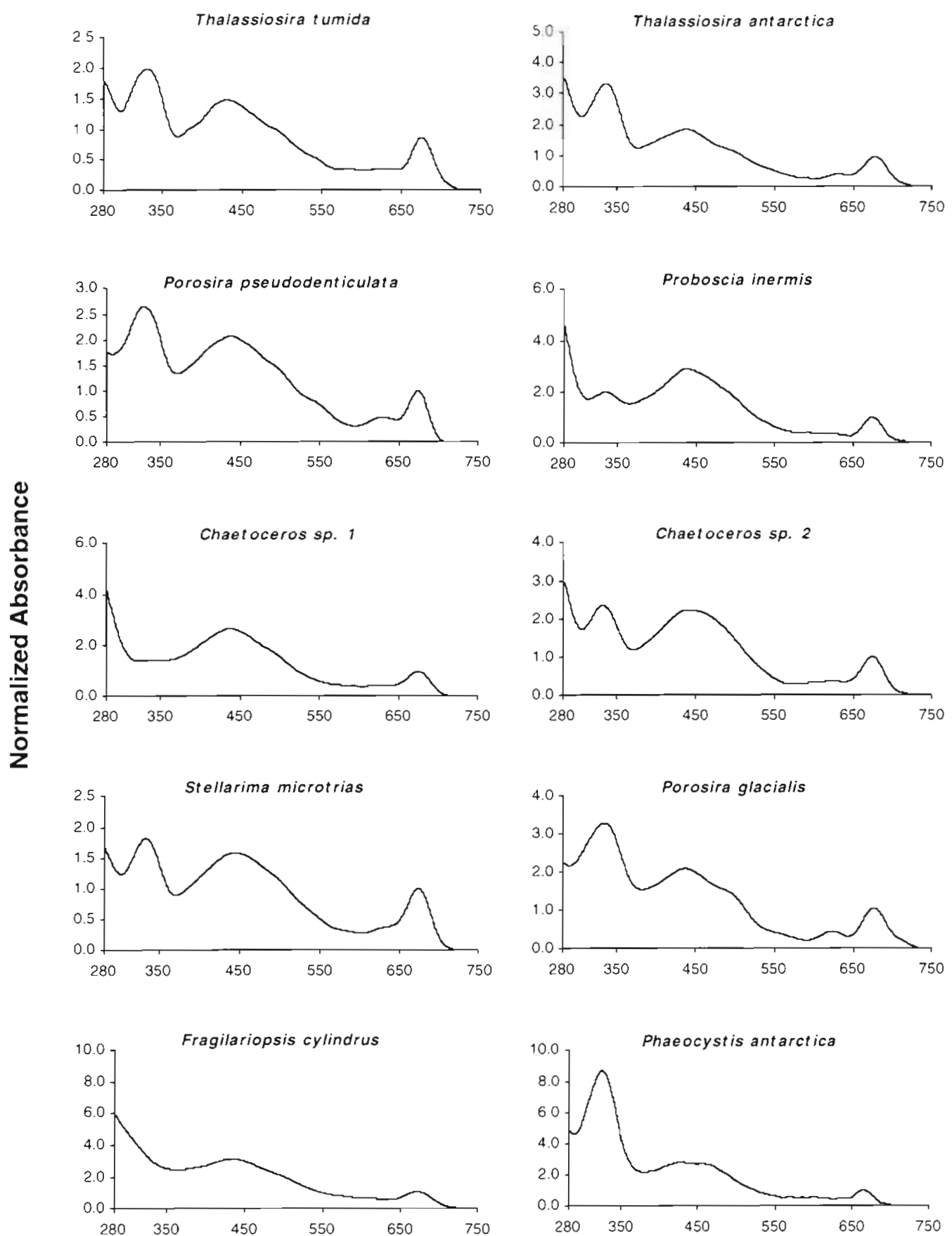

Wavelength $(\mathrm{nm})$

Fig. 2. In vivo algal absorption spectra of Antarctic diatoms and Phaeocystis antarctica, normalized to the red chlorophyll a peak at $676 \mathrm{~nm}$. The cultures were grown for a minimum of 5 generations under standard conditions of $100 \mu \mathrm{mol} \mathrm{photons}^{-2} \mathrm{~s}^{-1}$ of white-light illumination at $0^{\circ} \mathrm{C}$

tic phytoplankton (Villafane et al. 1995, Bidigare et al. 1996). In the present study, the relative proportion of individual MAAs for a given phytoplankton species showed little variation regardless of incubation condi- tions and was not affected by the quantity or spectral quality of light. MAA content per cell was strongly correlated to $a_{u v} / c e l l$ of ethanol extracts of diatom cells (Fig. 3), indicating that changes in absorption at the 

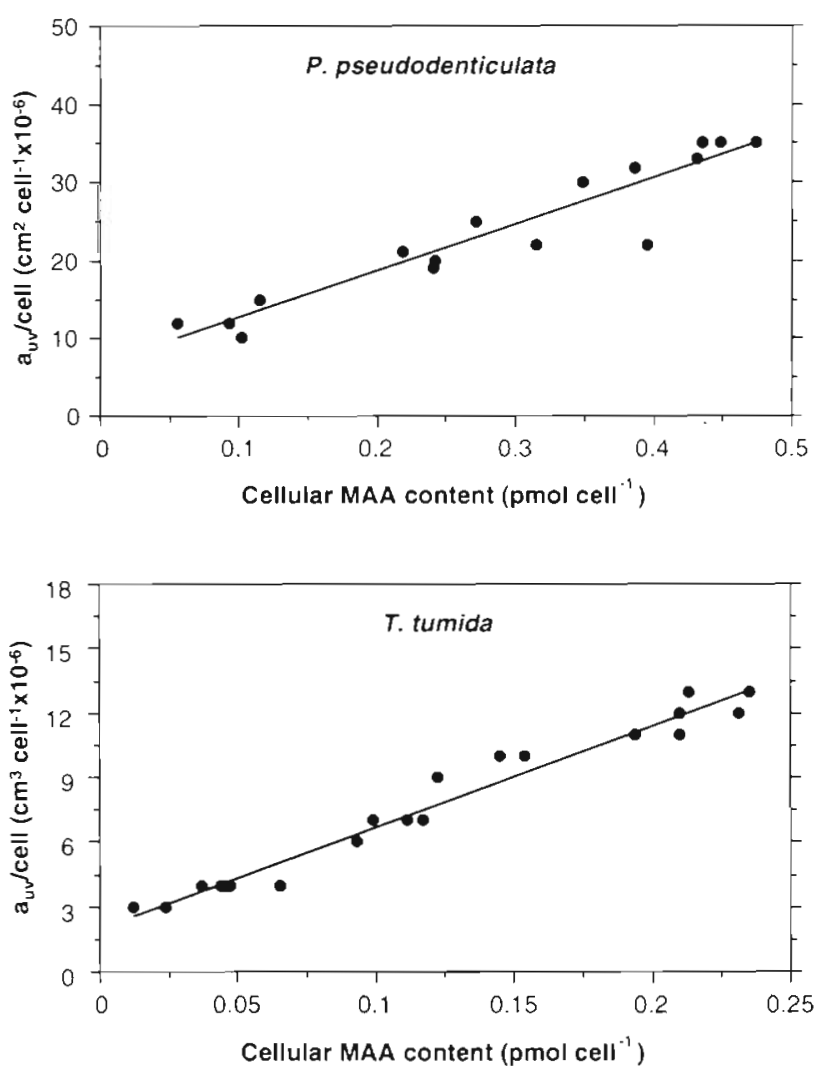

Fig. 3. Relationship between auv/cell and cellular content of MAAs. The solid line is a least-square regression fit of the data with an $\mathrm{r}^{2}$ of 0.94 for Porosira pseudodenticulata and 0.98 for Thalassiosira tumida. Note the different scales of axes

UV peak were due to MAA accumulation within the cells and supporting our use of $a_{U V} /$ cell as a relative measure of the cellular content of UV-absorbing compounds. Individual chemical species of MAAs could not be completely separated and identified from ethanol extracts of Phaeocystis antarctica. However, the substances eluted from the HPLC column exhibited absorption characteristics like those of MAAs. Bidigare et al. (1996) identified the MAA mycosporineglycine:valine in an Antarctic species of Phaeocystis based on the retention time and the absorbance spectra of compounds separated by HLPC. Therefore, we tentatively identify these substances as mycosporinelike amino acids.

The sunscreen factor, $S$, ranged from 0.03 to 0.94 for all species examined (Table 2), indicating that the potential for protection from the damaging effects of UVR varies greatly among species. In addition, $S$ determined for the diatoms and for Phaeocystis antarctica when colonies were used as the optical unit exhibited an increasing trend with larger cell radius, even among clones of the same species (Table 2, Fig. 4). This increase in $S$ with cell/colony radius was similar in shape to the curve for maximum $S$ (Fig. 4) predicted from the model of Garcia-Pichel (1994). That $S$ often fell below model predictions suggests that the maximum accumulation of MAAs was not always induced or that our values for $J_{\text {bkg }}$ (see Eq. 2) were too large. In either case, our estimate of $S$ is conservative. Alternately, the assumption of a maximum MAA content of $1 \%$ of dry cell weight to calculate maximum $S$ from the Garcia-Pichel model may have been too large. When $S$ was calculated for $P$. antarctica using cells as the optical unit, all values were far greater than the predicted upper limit of $S$.

\section{Induction of UV-absorbing compounds}

Induction of MAAs was observed for algal species grown under white-light illumination (Fig. 5). auv/cell was linearly correlated to irradiance levels, demonstrating the dependence of induction on photon fluency rate. MAA accumulation did not saturate at irradiances as great as $350 \mu \mathrm{mol}$ photons $\mathrm{m}^{-2} \mathrm{~s}^{-1}$. In contrast, auv/cell decreased with time (data not shown) in cultures grown under red light ( $>560 \mathrm{~nm}$ ) or yellow light (>460 nm), indicating that induction of MAAs was restricted to wavelengths less than $460 \mathrm{~nm}$. The decrease in $a_{U V} /$ cell was inversely proportional to the division rate, suggesting that MAAs became diluted through successive divisions rather than being actively destroyed. Consequently, cultures with a low MAA content were produced by continued growth under red or yellow light over several generations. The reduction in $a_{U V} /$ cell through successive divisions was also observed in cultures incubated in darkness (Fig. 6).

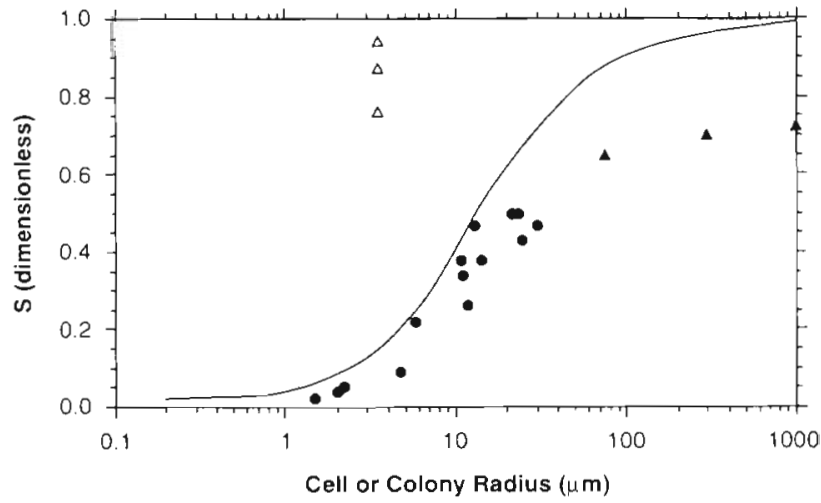

Fig. 4. Sunscreen factor $(S)$ versus diatom cell radius $(\bullet)$ and $P$ antarctica cell $(\Delta)$ and colony $(\Delta)$ radius. The solid line represents an estimate of maximum $S$ based on radius, assuming a MAA content of $1 \%$ cellular dry weight (Garcia-Pichel 1994) 

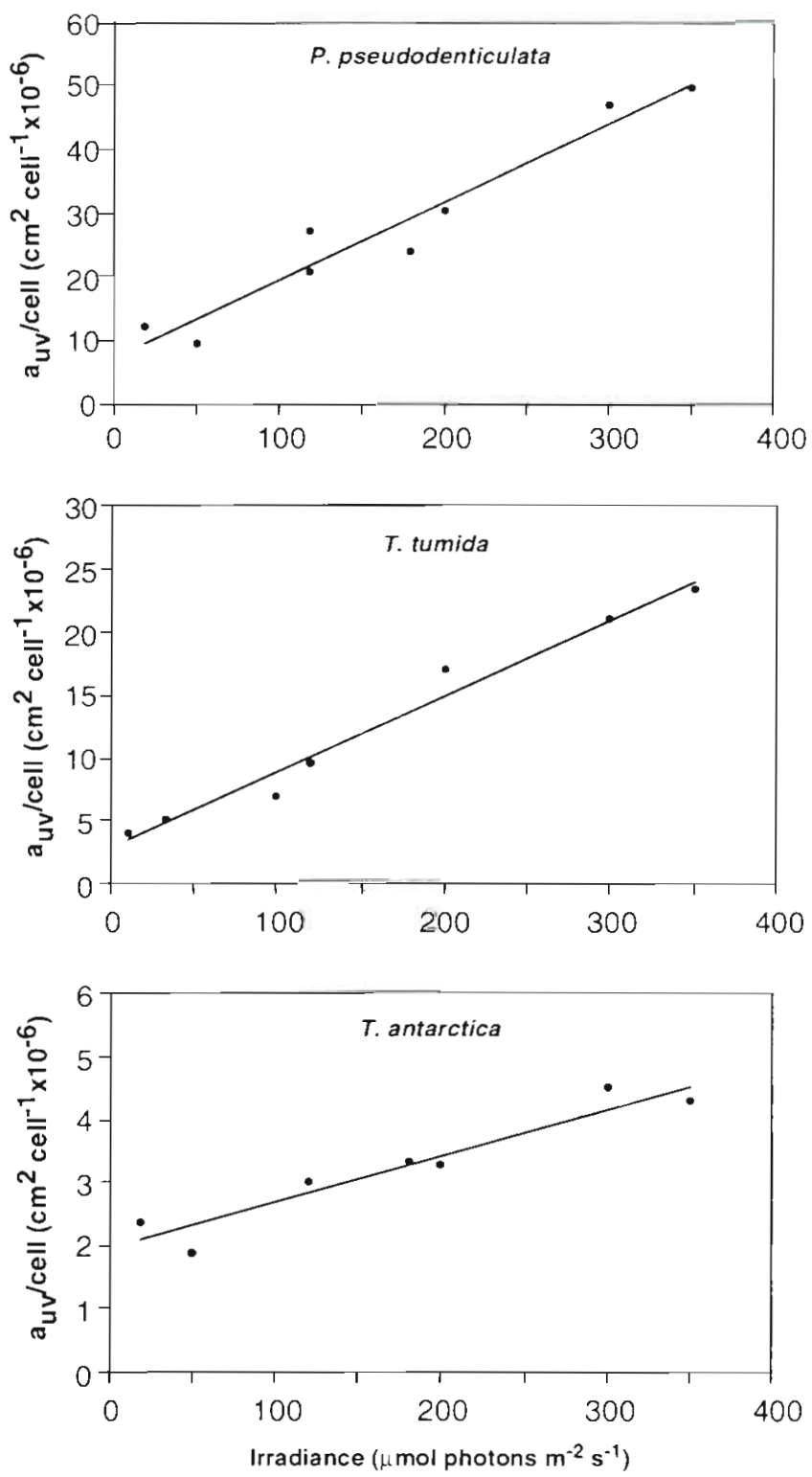

Fig 5. Relative cellular content of MAAs, measured as $a_{u v} /$ cell, in cultures of Porosira pseudodenticulata, Thalassiosira tumida, and $T$ antarctica that were grown for a minimum of 10 generations under white-light illumination ranging from 20 to $350 \mu \mathrm{mol}$ photons $\mathrm{m}^{-2} \mathrm{~s}^{-1}$ The solid lines are least-square regression fits of the data. Note the different scales on ordinates

During the first $10 \mathrm{~d}$ after being transferred to complete darkness, cultures of Thalassiosira antarctica and Porosira pseudodenticulata increased in cell number and decreased in $a_{\cup V} /$ cell. Decreases in $a_{U V} /$ cell were inversely proportional to cell number. No change in cell number or $a_{\cup v} /$ cell was observed from Day 10 through the end of the incubation on Day 62 , indicating that MAAs were stable and not broken down by the cell over a period of 2 mo. These species of diatoms are known to remain viable during extended darkness (Peters \& Thomas 1996), and when subsamples of our cultures were illuminated at any point during the dark incubation, photosynthetic and growth rates reverted to levels similar to those measured prior to the dark incubation

MAA accumulation was lower in cultures incubated under illumination where shorter wavelengths were selectively removed (Fig. 7). This reduced induction was not entirely the result of the reduction in total irradiance that accompanied restricting the illumination wavelengths (Table 1), as evidenced by the strong wavelength-dependence of the response curves of MAA accumulation (Fig. 8). For the diatoms, the radiation bands centered at 367 and $463 \mathrm{~nm}$ were most effective for induction of MAA accumulation. These 2 radiation bands include wavelengths from 344 to $493 \mathrm{~nm}$ (Figs. 1 \& 8), which are primarily in the UVA and blue portion of the electromagnetic spectrum. Radiation bands centered at 325 and $347 \mathrm{~nm}$, which overlap the UVB portion of the spectrum, induced only minor MAA accumulation. In contrast, the induction of MAAs in Phaeocystis antarctica was maximal in the radiation band centered at $347 \mathrm{~nm}$ and significant induction was observed in radiation bands centered at 325 and $367 \mathrm{~nm}$. These radiation bands include wave-
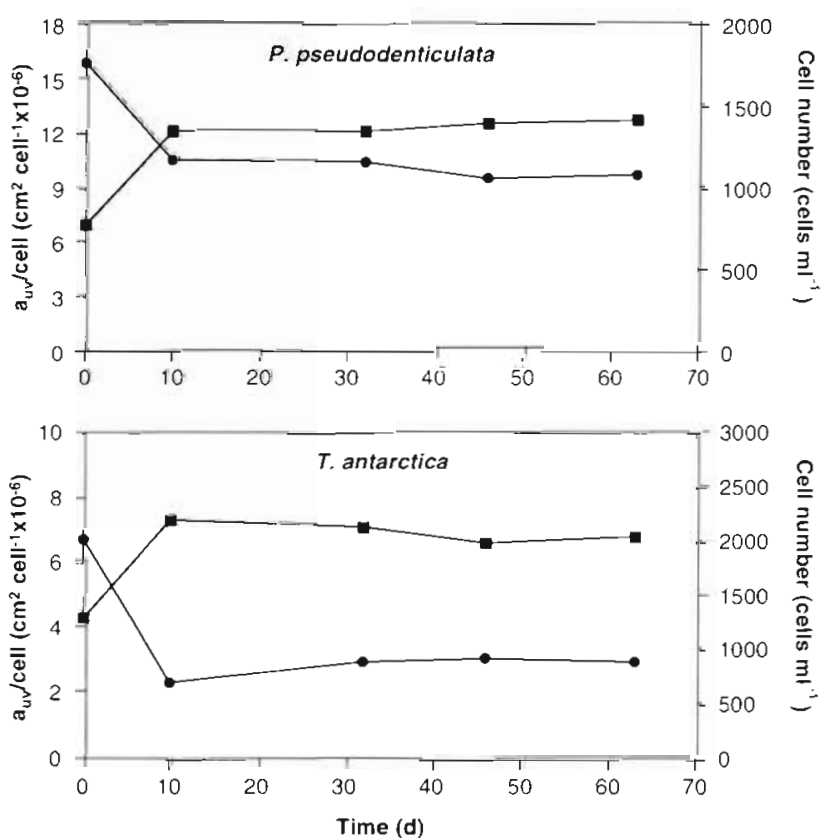

Fig. 6. Change in cell number ( $)$ and relative cellular content of MAAs $\left(\bullet, a_{U V} /\right.$ cell $)$ in cultures of Thalassiosira antarctica and Porosira pseudodenticulata that were incubated for 2 mo in total darkness. Before transfer to the dark the cultures were grown at a photon fluency rate of $100 \mu \mathrm{mol} \mathrm{m} \mathrm{m}^{-2} \mathrm{~s}^{-1}$ under white-light illumination. Note the different scales on ordinates 

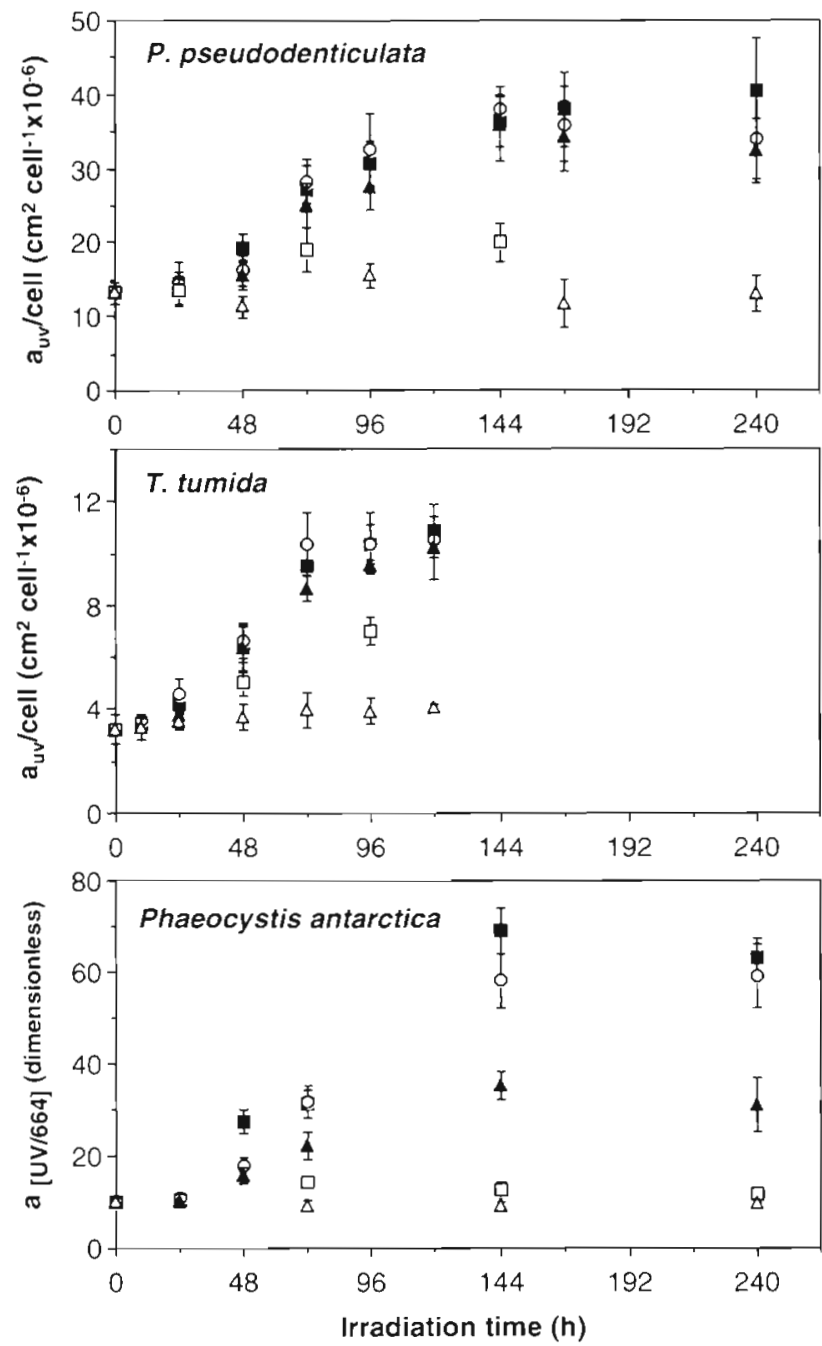

Fig. 7 Kinetics of the accumulation of UV-absorbing compounds for algal cultures incubated at 5 different spectral distributions. Accumulation was measured as auv/cell for Thalassiosira tumida and Porosira pseudodenticulata, and as $a_{\mathrm{UV}} / a_{\mathrm{G} 64}$ for Phaeocystis antarctica. Symbols are labeled numerically, corresponding to the spectra distributions presented in Fig. $1 \mathrm{~A}: \bullet=\mathrm{LF} 1, \mathrm{O}=\mathrm{LF} 2, \Delta=\mathrm{LF} 3, \mathrm{\square}=\mathrm{LF} 4, \triangle=\mathrm{LF} 5$ ). The error bars represent the standard deviation of 4 samples. Note the different scales on ordinates

lengths from 305 to $390 \mathrm{~nm}$, which primarily overlap the UVB and UVA portions of the spectrum. Bidigare et al. (1996), using broader and less defined wavelength bands, reported that MAAs were induced under PAR and UVA illumination in Antarctic diatom species, but that induction in Phaeocystis sp. was in response to UVA illumination.

The kinetics of MAA induction exhibited 3 distinct phases: an initial lag phase, during which UV absorption remained relatively unchanged; an exponential phase, during which UV absorption increased rapidly; and a steady-state phase, during which UV absorption

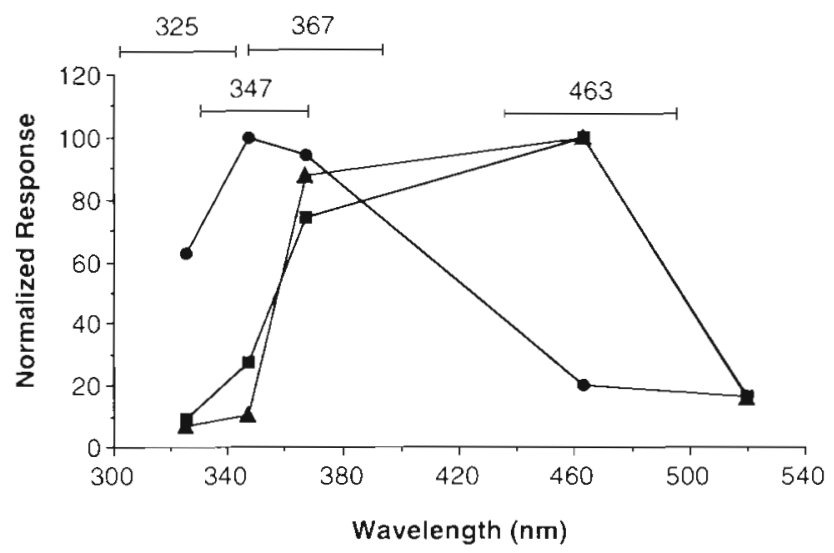

Fig. 8. Response spectra for the accumulation of UV-absorbing compounds determined for Thalassiosira tumida ( $\square$ ), Porosira pseudodenticulata (4) and Phaeocystis antarctica ( $\bullet$ ). The spectra have been normalized so that the highest value in each curve equals 100. Bars at the top of the graph represent the wavelength range containing $90 \%$ the energy in each irradiance band as described in Fig. 1A. The bars are labeled with the median wavelength of the irradiance bands

leveled off and remained relatively constant (Fig. 7). For Porosira pseudodenticulata and Phaeocystis antarctica, the lag phase ended after ca $24 \mathrm{~h}$ and the steady-state phase began ca $144 \mathrm{~h}$ after the onset of illumination. A shorter lag phase of ca $10 \mathrm{~h}$ was observed for Thalassiosira tumida and the steady-state phase began ca $72 \mathrm{~h}$ after the onset of illumination. For all cultures, illumination for up to $6 \mathrm{~h}$ followed by $24 \mathrm{~h}$ of darkness led to no measurable increase in UV absorption (data not shown), indicating that continuous illumination was required to induce increases in UV absorption.

\section{DISCUSSION}

A factor influencing the effectiveness of a UV sunscreen is the degree of correspondence between the in vivo absorption produced by the UV-absorbing compounds and the wavelengths of damaging UVR. In the present study, in vivo absorption of diatom cells attributable to MAAs showed maxima in the UVA and relatively strong absorption extending from 300 to $360 \mathrm{~nm}$, a range which corresponds to the UV wavelengths of greatest absolute photoinhibitory effect (Mitchell et al. 1989, Helbling et al. 1992, 1994 , Arrigo 1994, Cullen \& Neale 1994). However, absorption of light in these wavelengths is not a sufficient criterion to classify a compound as a UV sunscreen (Garcia-Pichel 1994). The total absorption of the compounds in vivo must be high enough to reduce significantly the potential damage from incoming radiation. Therefore, in addition to the absorption spectra, the 
intracellular concentration of UV-absorbing compounds and cell size also are important factors in regulating a sunscreen's protective capabilities. There are both physical and physiological limits to how concentrated small, water-soluble molecules such as MAAs can be in a cell. Physical limitations may be imposed by solubility, space constraints, and osmosis. Physiological limits may be set by toxicity and energetic investment for synthesis versus benefit. GarciaPichel \& Castenholz (1993) found that MAAs consistently accounted for $<1 \%$ of the dry biomass of cells of cyanobacteria and other microorganisms, and suggested that this cellular content may represent the approximate physiological limit of MAA accumulation (Garcia-Pichel 1994).

Considering this constraint on intracellular MAA content, the maximum effectiveness of a MAA as a sunscreen would depend largely on cell size, with the smallest phytoplankton cells recciving little or no protection from UV radiation. Garcia-Pichel (1994), using $S$ as a measure of sunsceening effectiveness, concluded that MAAs could be effective as sunscreens only for organisms with a radius of greater than $10 \mu \mathrm{m}$ $(S>0.4)$ and that for powerful and efficient sunscreen protection a radius of greater than $200 \mu \mathrm{m}(S>0.9)$ is required. Our results for diatoms, showing an increased potential for sunscreen protection. with cell size, are consistent with these conclusions. In addition, it is possible that MAAs are not synthesized or are not photoinducible in the smaller diatoms where MAA accumulation is an ineffective strategy for reducing UVR damage. For example, only trace amounts of specific MAAs could be detected in Chaetoceros sp. 1 , Fragilariopsis cylindrus and $F$ linearis (radius $<5 \mu \mathrm{m}$ ), regardless of incubation conditions. In contrast, MAA photoinduction was always observed in the larger diatoms.

The cell-size-dependancy of $S$ and MAA production observed for diatoms does not hold for the relatively small Phaeocystis antarctica cells (mean radius = $3.5 \mu \mathrm{m})$. $S$ values, calculated using the mean radius of the individual cells as the optical unit, were 7 - to 9fold greater than the theoretical maximum values calculated for cells the size of $P$. antarctica. We estimate that to attain such high values for $S$ (0.75 to 0.95), MAAs would have to comprise between 20 and $40 \%$ of total dry biomass of the $P$. antarctica cells, far greater then the upper limit of ca $1 \%$ total dry cellular biomass determined by Karentz et al. (1991b) and Garcia-Pichel \& Castenholz (1993). Marchant et al. (1991), noting that the concentrations of UV-absorbing compounds observed in the colonial phase of Phaeocystis pouchetii appear too high to be contained intracellularly, suggested that the compounds were located extracellularly, in association with the acellu- lar matrix in which colonial $P$. antarctica cells are embedded. The authors reported that the singlecelled phase of $P$. pouchetii, which lacks the acellular matrix, also lacks UV-absorbing compounds. Consistent with an extracellular location of these compounds, we note that recalculation of $S$ using colony radius (50 to $1400 \mu \mathrm{m}$ ) as the optical unit resulted in reasonable estimates for $S$ (ca 0.7; Fig. 4) and the percent of colony dry weight attributable to MAAs $(<1 \%)$. The ecological implications of extracellular accumulation of UV-absorbing compounds are substantial in that by adopting a colonial growth habit, small cells may obtain a benefit from UV screening that would otherwise be unavailable to them as single cells.

To be effective against UVR damage, a photoregulated protection process must respond to a portion of the electromagnetic spectrum that provides useful information about ambient levels of damaging UVR. Recent studies have shown that wavelengths in the UVA between 320 and $335 \mathrm{~nm}$ consistently provide the greatest absolute photoinhibitory effect of UVR in natural phytoplankton populations (Mitchell et al. 1989, Helbling et al. 1992, 1994, Arrigo 1994, Cullen \& Neale 1994). From our results, the production of MAAs in Antarctic diatoms and in Phaeocystis antarctica is a light-controlled process that displays a wavelength-dependent response, but peak responses are at wavelengths somewhat longer (345-460 nm; Fig. 8) than those inflicting the greatest damage. This phenomenon of a shift to longer wavelengths of the induction-response relative to the damage-response spectra is commonly observed in photoregulated UVprotection responses in higher plants and fungi (Beggs \& Wellmann 1994). In view of the rapid decrease in solar energy reaching the earth at wavelengths less than $330 \mathrm{~nm}$, such a shift may reflect a strategy to provide a sufficiently strong solar signal to initiate the induction processes (B. Prézelin pers. comm.). Cueing on the longer wavelengths would provide the proper signal for protection induction, assuming that the ratio of damaging to inducing wavelengths was relatively stable on an evolutionary time-scale (see below).

An important consideration is whether MAAs provide protection from the increase in UV radiation associated with the seasonal decrease in ozone over the Southern Ocean. In vivo algal absorption spectra (Fig. 2) and the absorption spectra for MAAs (Karentz et al. 1991b, Karentz 1994) correspond to some of the UVB wavelengths that are enhanced during ozone depletion. Values for $S$ as high as 0.22 to 0.30 for diatoms were observed at wavelengths between 300 and $320 \mathrm{~nm}$, indicating that MAAs provide diatoms some degree of protection from enhanced 
UVB. Nevertheless, the induction of MAAs in diatoms was most effective at wavelengths between 350 and $470 \mathrm{~nm}$, with very little response observed between 305 and $340 \mathrm{~nm}$. Consequently, for this induction system to adequately respond to an increase in UVB radiation, radiation in UVA and blue wavelengths (350 and $470 \mathrm{~nm}$ ) must increase proportionally to the UVB radiation. However, because of the wavelengthdependent absorption of ozone, enhancement of UVR during ozone depletion occurs primarily in the UVB range, without an equivalent increase in UVA or PAR. For example, a large decrease in atmospheric ozone from 360 to 140 DU would enhance UVB by $66 \%$, whereas UVA would increase by $<1 \%$ and primarily at wavelengths $<335 \mathrm{~nm}$ (determined from Arrigo 1994). PAR would also increase slightly, but at wavelengths greater than ca $500 \mathrm{~nm}$. Therefore, it is unlikely that MAA production would be induced sufficiently to provide additional protection to diatoms during an increase in UVB brought on by a reduction in atmospheric ozone (Smith et al. 1992, Prézelin et al. 1994).

In contrast, the potential for protection from UVB radiation by MAAs is greater for Phaeocystis antarctica. Compared to the diatoms, P. antarctica exhibited a higher absorption in the UV wavelengths and absorption peaks were shifted more towards the UVB (Fig. 2). In addition, the response spectra for MAA accumulation in $P$. antarctica exhibited a maximum at ca $340 \mathrm{~nm}$ and significant induction at wavelengths as short as $305 \mathrm{~nm}$. Therefore, accumulation of MAAs with strong absorption in the UVB may be induced in response to elevated UVB during ozone depletion events. This higher potential for protection from UVB damage may help explain the colonial $P$. antarctica bloom observed in the Ross Sea during the austral spring (Smith \& Gordon 1997) when ozone depletion is greatest. In contrast, studies conducted under artificial and ambient light indicate that Phaeocystis species appear to have greater sensitivity to UVB exposure than Antarctic diatom species (Marchant et al. 1991, Smith et al. 1992, Davidson et al. 1994, Karentz \& Spero 1995). UVB inhibition of growth rate was reported to be higher for Phaeocystis sp. than for the diatom Chaetoceros socialis (Smith et al. 1992). Karentz \& Spero (1995) reported a reduction in cell density of Phaeocystis sp. in the marginal ice-edge zone that was correlated to a reduction in ozone concentration and suggested that cell death was due to increased exposure to UVB. Whereas these observations appear to be in conflict with ours, we note that our study reports only the potential for UV protection based on absorption characteristics and that very little is known about the protective qualities of MAAs. In addition, phytoplankton survival under high UVB is the result of a complex suite of cellular mechanisms including protection, repair, and avoidance responses. Therefore, observations of UVB sensitivity may not directly correlate to the potential benefits of any single response.

The accurate assessment of the effectiveness of this UV-protection mechanism is complex. Action and response spectra give some idea about the potential for damage and protection under a constant light field. However, the light field experienced by a phytoplankter will vary considerably due to annual and diurnal changes in sun angle and, in particular, due to turbulent mixing in the water column (Kirk 1994). For instance, Cullen \& Lesser (1991) have demonstrated that for equal doses of UVB radiation, short exposures to high irradiance are more damaging than longer exposures to lower irradiance. Consequently, in a rapidly mixing water column, UVR damage to phytoplankton that are approaching the surface may be particularly acute, especially in light of the lag time observed for the induction of MAA accumulation. Alternately, the ratio of UVA/UVB and blue light/UVB increases with depth. Therefore, for ascending phytoplankton exhibiting a MAA induction response in the UVA/blue portion of the spectrum (Figs. $7 \& 8$ ), our data indicate that the accumulation of MAAs begins at depth before the cells rise near the surface where the potential for UVB damage is greater. Further intricacies are introduced by the interdependence of growth rate, MAA induction, and MAA accumulation. For instance, whereas MAA accumulation that is induced under high UVR may provide protection from UVR and presumably enhance growth rate, enhanced growth rate dilutes MAA content, thereby reducing the potential for protection.

The complexity of such scenarios dramatically increases when species composition (Table 2) and additional UVR protection and repair mechanisms (Karentz et al. 1991a) are considered, pointing out the need for a comprehensive approach for studying the influence of UVR on phytoplankton ecology. In this study of UV-absorbing compounds, we examined the kinetics and spectral response of accumulation and the potential for a sun screening function, based on absorption characteristics, for a variety of phytoplankton species. Additional research monitoring specific cellular targets for UVR or indicators of overall phytoplankton health, such as photosynthesis or growth rate, must be carried out to determine if the potential for protection and repair translates quantitatively into mitigation of UVR damage. Coupling this information to a modeling effort that includes other protection and repair mechanisms in a dynamic environment may be crucial to understanding the overall effect of UV radiation on phytoplankton populations. 
Acknowledgements. We thank $H$. Schwarz and M. Baumann for making the culture material available to us, Y. Grams for helping with several analyses, $T$ Hanken for measuring the spectral irradiance, and F. Garcia-Pichel for providing the MAA-standards. B. Kroon and K. Arrigo provided critical comments on the manuscript. This is publication no. 1310 of the Alfred Wegener Institute for Polar and Marine Research, Bremerhaven

\section{LITERATURE CITED}

Arrigo KR (1994) Impact of ozone depletion on phytoplankton growth in the Southern Ocean: large-scale spatial and temporal variability. Mar Ecol Prog Ser 114:1-12

Beggs CJ, Wellmann E (1994) Photocontrol of flavonoid biosysthesis. In: Kendrick RE, Kronenberg GHM (eds) Photomorphogenesis in plants, 2nd edn. Kluwer Academic Publisher, Dordrecht, p 733-750

Bidigare RR, Iriarte JL, Kang SH, Ondrusek ME, Karentz D, Fryxell GA (1996) Phytoplankton: quantitative and qualitative assessments. In: Ross R, Hofmann E, Quetin L (eds) Foundations for ecosystem research in the western Antarctic peninsula region. Antarctic Res Ser Vol 70 , American Geophysical Union, Washington, DC, p $173-198$

Caldwell MM, Robberecht R, Flint SD (1983) Internal filters: prospects for UV-acclimation in higher plants. Physiol Plant 58:445-450

Carreto JI, Carignan MO, Daleo G, De Marco SG (1990a) Occurrence of mycosporine-like amino acids in the redtide dinoflagellate Alexandrium excavatum: UV-photoprotective compounds? J Plankton Res 12:909-921

Carreto JI, Lutz VA, De Marco SG, Carignan MO (1990b) Fluence and wavelength dependence of mycosporine-like amino acid synthesis in the dinoflagellate Alexandrium excavatum. In: Graneli E, Edler L, Sundström B, Anderson DM (eds) Toxic marine phytoplankton. Elsevier, New York, p 275-279

Cullen JJ, Lesser MP (1991) Inhibition of photosynthesis by ultraviolet radiation as a function of dose and dosage rate: results for a marine diatom. Mar Biol 111:183-190

Cullen JJ, Neale PJ (1994) Uitraviolet radiation, ozone depletion, and marine photosynthesis. Photosyn Res 39:303-320

Davidson AT, Bramich D, Marchant HJ, McMinn A (1994) Effects of UV-B irradiation on growth and survival of Antarctic marine diatoms. Mar Biol 119:507-515

Dunlap WC, Chalker BE (1986) Identification and quantification of near-UV absorbing compounds (S-320) in a hermatypic scleractinian. Coral Reefs 5:155-159

Dunlap WC, Chalker BE, Oliver JK (1986) Bathymetric adaptations of reef-building corals at Davies Reef, Great Barrier Reef, Australia. III. UV-B absorbing compounds. J Exp Mar Biol Ecol 104:239-248

Evans CA, O'Reilly JE, Thomas JP (1987) A handbook for the measurement of chlorophyll a and primary production. Biomass 8, Texas A\&M University, College Station

Garcia-Pichel F (1994) A model for internal self-shading in planktonic organisms and its implication for the usefulness of ultraviolet sunscreens. Limnol Oceanogr 39: $1704-1717$

Garcia-Pichel F, Castenholz RW (1993) Occurrence of UVabsorbing, mycosporine-like compounds among cyanobacterial isolates and an estimate of their screening capacity. Appl Environ Microbiol 59:163-169

Helbling EW, Chalker BE, Dunlap WC, Osmund $\mathrm{HH}$, Villafane VE (1996) Photoacclimation of Antarctic marine diatoms to solar ultraviolet radiation. J Exp Mar Brol Ecol 204:85-101

Helbling EW, Villafane V, Ferrario M, Holm-Hansen O (1992) Impact of natural ultraviolet radiation on rates of photosynthesis and on specific marine phytoplankton species. Mar Ecol Prog Ser 80:89-100

Helbling EW, Villafane V, Holm-Hansen O (1994) Effects of ultraviolet radiation on Antarctic marine phytoplankton photosynthesis with particular attention to the influence of mixing. In: Weiler CS, Penhale PA (eds) Ultraviolet radiation and biological research in Antarctica. American Geophysical Union, Washington, DC, p 207-227

Ito S, Hirata $Y(1977)$ Isolation and structure of a mycosporine from the zoanthid Palythoa tuberculosa. Tetrahedron Lett 28:2429-2430

Karentz D (1994) Ultraviolet tolerance mechanisms in Antarctic marine organisms. In: Weiler CS, Penhale PA (eds) Ultraviolet radiation and biological research in Antarctica, American Geophysical Union, Washington, DC, p 93-110

Karentz D, Cleaver JE, Mitchell DL (1991a) Cell survival characteristics and molecular responses of Antarctic phytoplankton to ultraviolet-B radiation. J Phycol 27:326-341

Karentz D, McEuen FS, Land MC, Dunlap WC (1991b) Survey of mycosporine-like amino acid compounds in Antarctic marine organisms: potential protection from ultraviolet exposure. Mar Biol 108:157-166

Karentz D. Spero HJ (1995) Response of a natural Phaeocystis population to ambient fluctuations of UVB radiation caused by Antarctic ozone depletion. J Plankton Res 17: $1771-1789$

Kirk JTO (1994) Light and photosynthesis in aquatic ecosystems, 2nd edn. Cambridge University Press, Cambridge

Marchant HJ, Davidson AT, Kelly GJ (1991) UV-B protecting compounds in the marine alga Phaeocystis pouchetii from Antarctica. Mar Biol 109:391-395

Mitchell BG, Vernet M, Holm-Hansen O (1989) Uitraviolet light attenuation in Antarctic waters in relation to particulate absorption and photosynthesis. Antarct J US 24: $179-181$

Nakamura H. Kobayashi J, Hirata Y (1982) Separation of mycosporine-like amino acids in marine organisms using reversed-phase high-performance liquid chromatography. J Chromatogr 250:113-118

Peters E, Thomas DN (1996) Prolonged darkness and diatom mortality I: Marine Antarctic species. J Exp Mar Biol Ecol $207: 25-41$

Prézelin BB, Boucher NP. Smith RC (1994) Marine primary production under the influence of the Antarctic Ozone Hole: Icecolors '90. In: Weiler CS, Penhale PA (eds) Ultraviolet radiation and biological research in Antarctica. American Geophysıcal Union, Washington, DC, p $159-186$

Rousseau V, Vaulot D, Casotti R, Cariou V, Lenz J, Gunkel J, Baumann MM (1994) The life cycle of Phaeocystis (Prymnesiophyceae): evidence and hypotheses. J Mar Syst 5: $23-39$

Sancar A, Sancar GB (1988) DNA repair enzymes. Annu Rev Biochem 28(57):29-67

Shick JM, Dunlap WC, Chalker BE, Banaszak AT, Rosenzweig T.K (1992) Survey of ultraviolet radiation-absorbing mycosporine-like amino acids in organs of coral reef holothuroids. Mar Ecol Prog Ser 90:139-148

Smith RC, Prézelin BB, Baker KS, Bidigare RR, Boucher NP, Coley T, Karentz D, MacIntyre S, Matlick HA, Menzies D, Ondrusek M. Wan Z, Waters KJ (1992) Ozone depletion: ultraviolet radiation and phytoplankton biology in Antarctic waters. Science 255:952-959 
Smith WO, Gordon LI (1997) Hyperproductivity of the Ross Sea (Antarctica) polynya during the austral spring. Geophys Res Lett 24:233-236

Stapleton AE, Walbot V (1994) Flavonoids can protect maize DNA from the induction of ultraviolet radiation damage. Plant Physiol 105:881-889

Stosch JA von, Drebes G (1964) Entwicklungsgeschichtliche Untersuchungen an zentrischen Diatomeen. IV. Die Planktondiatomee Stephanopyrix turris, ihre Behandlung und Entwicklungsgeschichte. Helgol Wiss Meeresunters 11:209-257

Strid A, Chow WS, Anderson JM (1994) UV-B damage and protection at the molecular level in plants. Photosynth Res $39: 475-489$

Takano S, Uemura D, Hirata Y (1978) lsolation and structure of new amino acids, palythinol and palythene, from zoanthid Palythoa tuberculosa. Tetrahedron Lett 49:4909-4912

Tüg H, Baumann MEM (1994) Problems of UV-B radiation measurements in biological research. Critical remarks on current techniques and suggestions for improvements.

Editorial responsibility: Osmund Holm-Hansen (Contributing Editor), La Jolla, California, USA
Geophys Res Lett 21:689-692

Utermöhl H (1958) Zur Vervollkommnung der quantitativen Phytoplankton-Methodik. Int Ver Theor Angew Limnol Mitt 9:1-38

Vernet M. Brody EA, Holm-Hansen O, Mitchell BG (1994) The response of Antarctic phytoplankton to ultraviolet radiation: absorption, photosynthesis, and taxonomic composition. In: Weiler CS, Penhale PA (eds) Ultraviolet radiation and biological research in Antarctica. American Geophysical Union, Washington, DC, p 143-158

Vernet M, Mitchell BG, Holm-Hansen O (1989) Ultraviolet radiation in Antarctic waters: response of phytoplankton pigments. Antarct J US 24:181-183

Villafane VE, Helbling EW, Holm-Hansen O, Chalker BE (1995) Acclimatization of Antarctic natural phytoplankton assemblages when exposed to solar ultraviolet radiation. $J$ Plankton Res 17:2295-2306

Vincent WF, Roy $S$ (1993) Solar ultraviolet-B radiation and aquatic primary production: damage, protection, and recovery. Environ Rev 1:1-12

Submitted: May 23, 1997; Accepted: October 7, 1997 Proofs received from author(s): December 2, 1997 